
Periodica Polytechnica
Civil Engineering

62(1), pp. 180-190, 2018

https://doi.org/10.3311/PPci.10541

Creative Commons Attribution (i)

RESEARCH ARTICLE

\section{Experimental Investigation on Condition Monitoring Opportunities of Tramway Tracks}

\author{
Ákos Vinkó ${ }^{1 *}$, Péter Bocz ${ }^{1}$
}

Received 25 January 2017; Revised 12 April 2017; Accepted 27 June 2017

\begin{abstract}
The increasing demands for guided transportation modes in urban areas generate the need of high-frequency services. Due to the frequent services, the track deterioration process will be accelerated. Therefore, the exact knowledge of track quality is highly important for every railway company to provide high quality service level. For monitoring of tramway tracks, an unconventional vehicle dynamics measurement setup is developed, which records the data of 3-axes wireless accelerometers mounted on wheel discs of regular in-service tram. In the implementation of prototype system, the bogie side-frame and car body mounted sensors are also fitted to the instrumented vehicle to compare the efficiency of these conventional solutions with the developed arrangement. At the first test period, the instrumented vehicle works as a dedicated inspection vehicle, in order to keep the constant velocity and help to determine the influencing factors on results. Accelerations are processed to obtain the track irregularities, in order to determine whether the track needs to be repaired. Real data come from measurements taken on tram line 49 of the Budapest (Hungary) and they have been validated by comparing results to the actual state of the track provided by a track geometry monitoring trolley and visual inspection. This paper presents the developed methods used for validation and the analysis of preliminary results of the wheel discs mounted accelerometers. This vehicle dynamic measurement system is cheap to implement and no significant modification of the vehicle is required. Therefore, in-service vehicles equipped with this system may serve a good opportunity for monitoring tramway track, while it multiple passes over same track section.
\end{abstract}

\footnotetext{
Keywords

1 Department of Highway and Railway Engineering

Faculty of Civil Engineering,

Budapest University of Technology and Economics

Müegyetem rkp. 3, H-1111 Budapest, Hungary

* Correspondent author email: vinko.akos@epito.bme.hu
}

tramway track condition monitoring, spectral analysis, vibration, multi-criteria track rating system, vehicle dynamics measurements, un-loaded track geometry measurement, field measurement

\section{Introduction and motivation}

The methods and instruments of track condition assessment have been steadily developed over the years. First only visual observation and practical experience are used for determining track quality. This type of assessment highly depends on the person, who performs the evaluation, even if the multi-criteria track rating system is well-developed. Therefore, the measurements based assessments have been developed, which ensure the objective estimation of track quality. Track condition monitoring and assessment have been a deeply studied problem for many years and extensive literature is now available. [1] to [5]. Basically, four different monitoring systems exist [6]: infrastructurebased infrastructure monitoring, rolling-stock-based infrastructure monitoring, rolling-stock-based rolling stock monitoring, and infrastructure-based rolling stock monitoring. Dedicated measurement trains are normal in many railway administrations for assessing the condition of the track [7], and there are some examples, where simplified versions of these measuring systems have been fitted to service vehicles [8] to [11].

The automatic under load condition monitoring of tramway's track has not been applied in Hungary due to the lack of track recording car [12]. Nowadays the Hungarian practice of tramway track condition assessment is only suitable for identifying safety-critical defects, which are detected during visual inspection on track.

The authors carried out an extensive experimental activity on a selected tram line, where an unconventional vehicle dynamics measurement setup is used to detect track irregularities and its results are compared to experiments taken with track geometry monitoring trolley and visual inspection on same track. The next sections describe the main characteristics of the tram line, on which tests have been performed. Furthermore, details are given about the measurement set-up adopted for experiments in un-loaded state with track geometry measuring trolley, as well as in loaded state with the running tram. Then, test results are intended to face with the comparison of applied methods to give the main conclusions and further issues on the considered possibilities for development of the currently used tramway track condition assessment in Budapest. 


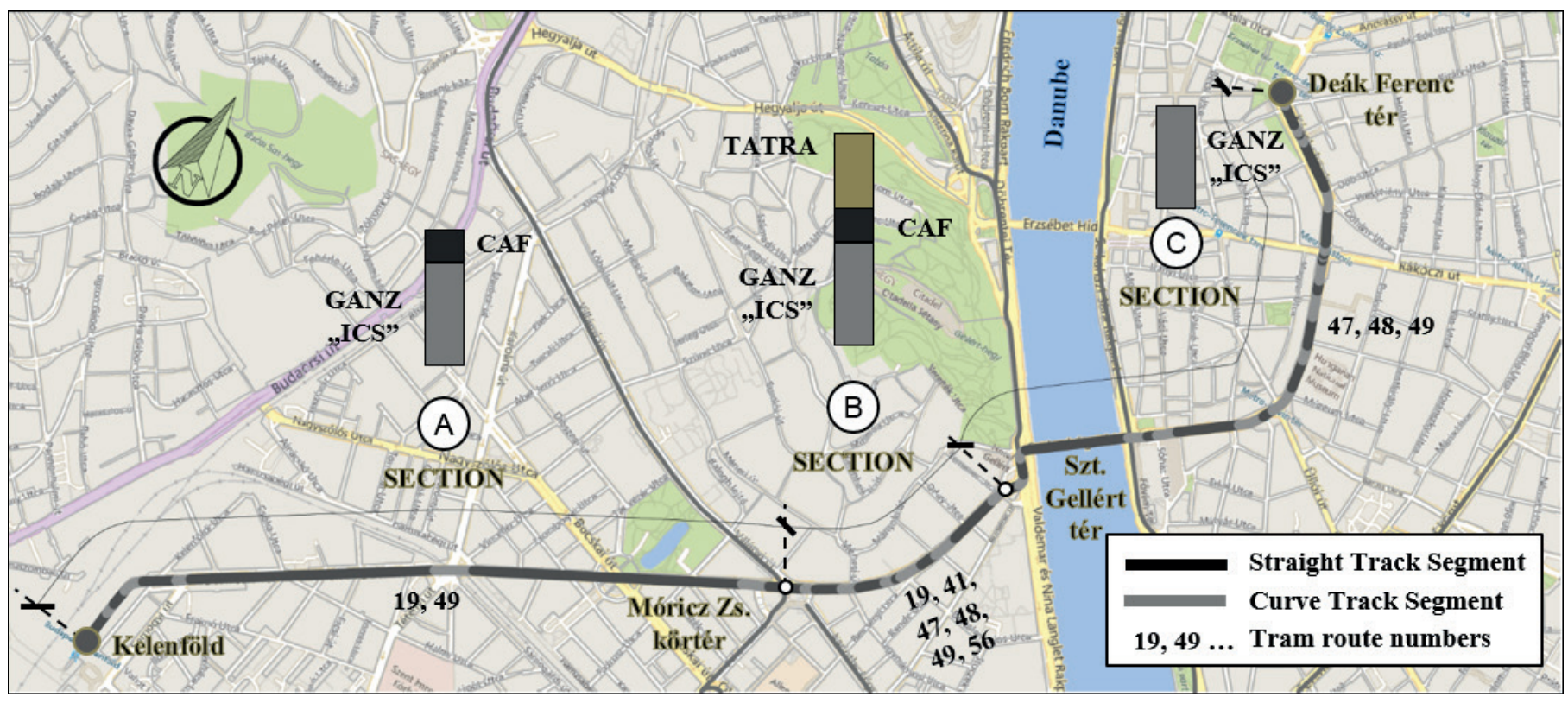

Fig. 1 The main charachteristics of the investigated tram line in downtown Budapest: homogenious traffic sections (A, B, C) and their alignment segments. Tram vehicle fleet composition per sections [Landscape data from Bing map]

\section{The investigated tram line}

There are several required aspects in the case of selecting the investigated tram line: the superstructure along the line should be widely applied in different traffic situations (from low to high-frequented lines) and sufficient maintenance experience of the track should be available for track inspectors.

The tests were performed in spring 2016 along the Budapest tram line 49 (See in Fig. 1), which is one of the most frequented lines of downtown. Along this tram line different track types can be found. The significant part of the track was grooved rail formed Embedded Rail Fastening System (ERFS), but in sharp curves, on the bridge and on turnouts there are special track structures.

There is an intertwining section in the middle part (see Section B in Fig. 1) of the line, where various tram routes join from south. According to traffic situation (daily rolled tonnage) the investigated tram line can be divided into three homogeneous sections: Section A (8089 tonne/day), where 2 tram routes, Section B (20618 tonne/day), where 6 tram routes, and Section C (9735 tonne/day), where 3 tram routs run. The daily rolled tonnage is computed based on the BKK (Centre for Budapest Transport). timetable March 2016. Composition of tram vehicle fleet running on tram line 49 is different along the sections: while in Section A and Section C GANZ type old articulated trams run predominantly, on Section B GANZ, TATRA and CAF type trams also run. This factor is highly important, because there is a strong relation among the life time (built and re-built year) of the superstructure, the rail traffic load and the track quality in terms of the vehicle-track interaction. There are significant differences in the life time of superstructure along the line: Section $B$ is the oldest and Section $C$ is the newest. (See Fig. 2).

\section{Theory \& Methodology}

The investigated tram line is divided into alignment segments based on its horizontal alignment (straight, circular curve and circular curve with transition curve segments) and the overall track quality of these track segments is assessed separately in each case.

For monitoring of track segments, an unconventional vehicle dynamics measurement setup is developed (Objective method), which records the data of 3-axes wireless accelerometers mounted on wheel discs and bogie side frame. At the first test period, the instrumented vehicle works as a dedicated inspection vehicle, in order to keep the constant velocity and help to determine the influencing factors on results. The prototype system has been validated by comparing results to the actual state of the track provided by a track geometry monitoring trolley (Quasi-objective method) and visual inspection on track (Subjective method).

In the case of subjective method, a Multi-criteria Track Rating System [13] is worked out, which ensures to identify the deterioration rate of each track segments using a scale from 0 point (excellent track quality) to 5 points (poor track quality). The evaluation is based on visual inspection on track and practical experiences.

In the case of quasi-objective method, the local track quality is assessed by means of scoring track geometrical segments based on admissible limits of track parameters. The TrackScan type track geometry measuring trolley [14] is used for the test. During the measurements, the track is unloaded, which means that this method is not suitable to measure the track dynamic response forming from tram-track interaction.

The methods for condition monitoring and assessment of track quality will be discussed in the next sections. 


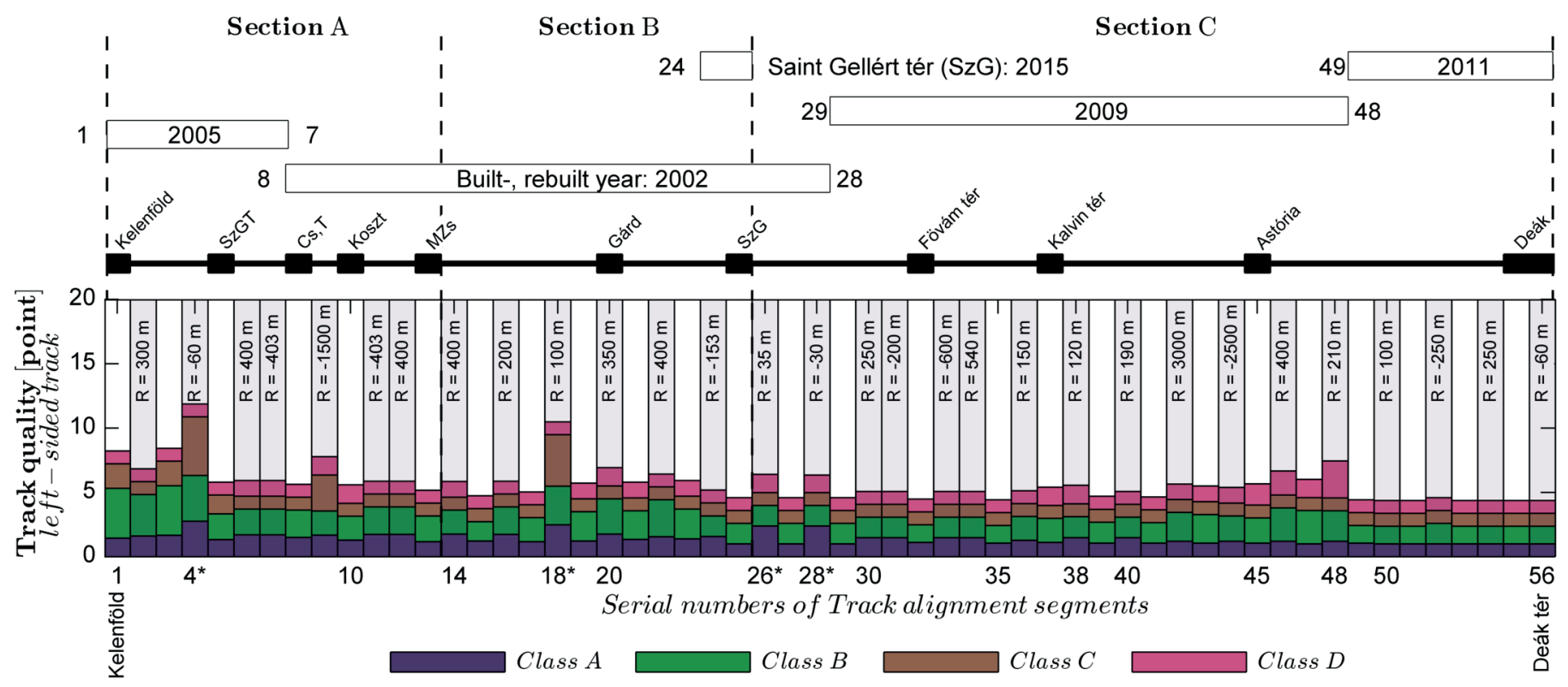

Fig. 2 At the top: built/last re-built year of track alignment segments; at the bottom: category-rated track quality (in points) computed per alignment segments of the left-sided track according to Subjective Track Condition Assessment Method (discription of classes in Table 1); *significant rail sidewear on curve

\section{Track condition monitoring in un-loaded state 4.1 Subjective method}

Subjective Track Condition Assessment Criterion System is developed based on experiences of visual inspections on track. The investigated track sections were built between 2002 and 2015 (See Fig. 2). Due to the different stage of lifetime and rail traffic situation the track defects can be easily observed from its start phase to deteriorated level on the investigated line sections.

Developing a categorised criterion system is the first step of subjective scoring of track quality. These criteria are continuously being collected during the visual inspection on tram line 49. They are defined based on specific observed defects of ERFS superstructure elements. The next step is the preference ranking of criteria according to a basic preference ranking method, as well as consultation with track experts. It should be noted that preference rank of criteria can change in a wide range depending on scenarios (examples include: short-, or long-term maintenance strategy, derailment safety, cost-effectiveness). In this case, the derailment safety is selected as the most important criterion. The subjective criteria can be divided into four large categories:

Class A: Condition and service quality of rails;

Class B: Condition of track structural elements;

Class C: Track irregularities;

Class D: Track defect forming from vehicle-dynamic loads.

The defined categories are not independent, because the deterioration process of track is a self-exciting cyclic process between the vehicle and track. Table 1 shows the categorised criteria and their corresponding average preference rank. The rank shows the importance of a given criterion. The investigated tram line sections are divided into geometrical segments according to horizontal alignment (straight-, curve segments).
These geometrical elements are rated by criteria on a scale from 0 point to 5 points. In every case the 0 point means the post-construction condition, 1 point the excellent quality, and in the case of 5 points the track is in highly poor condition. The scales meaning poor, average and excellent quality are separately specified in the case of every criterion. Between the defined scales subjective visual interpolation is used to determine the corresponding points. The weighted sum of criteria points according to corresponding preference rank provides the actual quality of each geometrical element within the line section. The Track quality of the whole line section can be computed by length-weighted value of each geometrical element within the section.

Table 1 The defined categorised-criteria for Subjective Condition Assessment

\begin{tabular}{|c|c|c|c|}
\hline \multicolumn{3}{|r|}{ Criteria for subjective scoring of track technical state } & \multirow{2}{*}{$\begin{array}{c}\begin{array}{c}\text { Prefer- } \\
\text { encerank }\end{array} \\
13,2 \%\end{array}$} \\
\hline \multirow{5}{*}{$\begin{array}{l}\varangle \\
w \\
0 \\
\Xi \\
0\end{array}$} & A1: & Partly and full cross section rail breaks and cracks & \\
\hline & A2: & Rail head side- and vertical wearing & $9,2 \%$ \\
\hline & A3: & Condition of grooved rail grooved head & $8,4 \%$ \\
\hline & A4: & Rail corrugation (on rail surface, gauge side, field side) & $6,6 \%$ \\
\hline & A5: & Rail surface defects (Squats, spells, RCF) & $5,2 \%$ \\
\hline \multirow{4}{*}{ 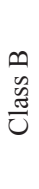 } & B1: & Drainage structures, design and maintenance deficiencies & $7,4 \%$ \\
\hline & B2: & Surface condition of pavement layer next to rail & $5,4 \%$ \\
\hline & B3: & Deterioration of Joint filling Bitumen & $4,6 \%$ \\
\hline & B4: & Deterioration of rubber filler profiles & $4,0 \%$ \\
\hline \multirow{2}{*}{$\begin{array}{l}0 \\
\text { 0ิ } \\
0 \\
0 \\
\end{array}$} & C1: & Visible vertical track irregularities & $8,8 \%$ \\
\hline & $\mathrm{C} 2$ : & Visible lateral track irregularities & $10,4 \%$ \\
\hline \multirow{3}{*}{$\begin{array}{c}0 \\
0 \\
0 \\
0 \\
0\end{array}$} & D1: & Additional dynamic load from vehicles at joining track & $6,2 \%$ \\
\hline & D2: & The infringement of tram traffic regulation & $5,2 \%$ \\
\hline & D3: & Sharing the track with Street traffic & $3,4 \%$ \\
\hline
\end{tabular}




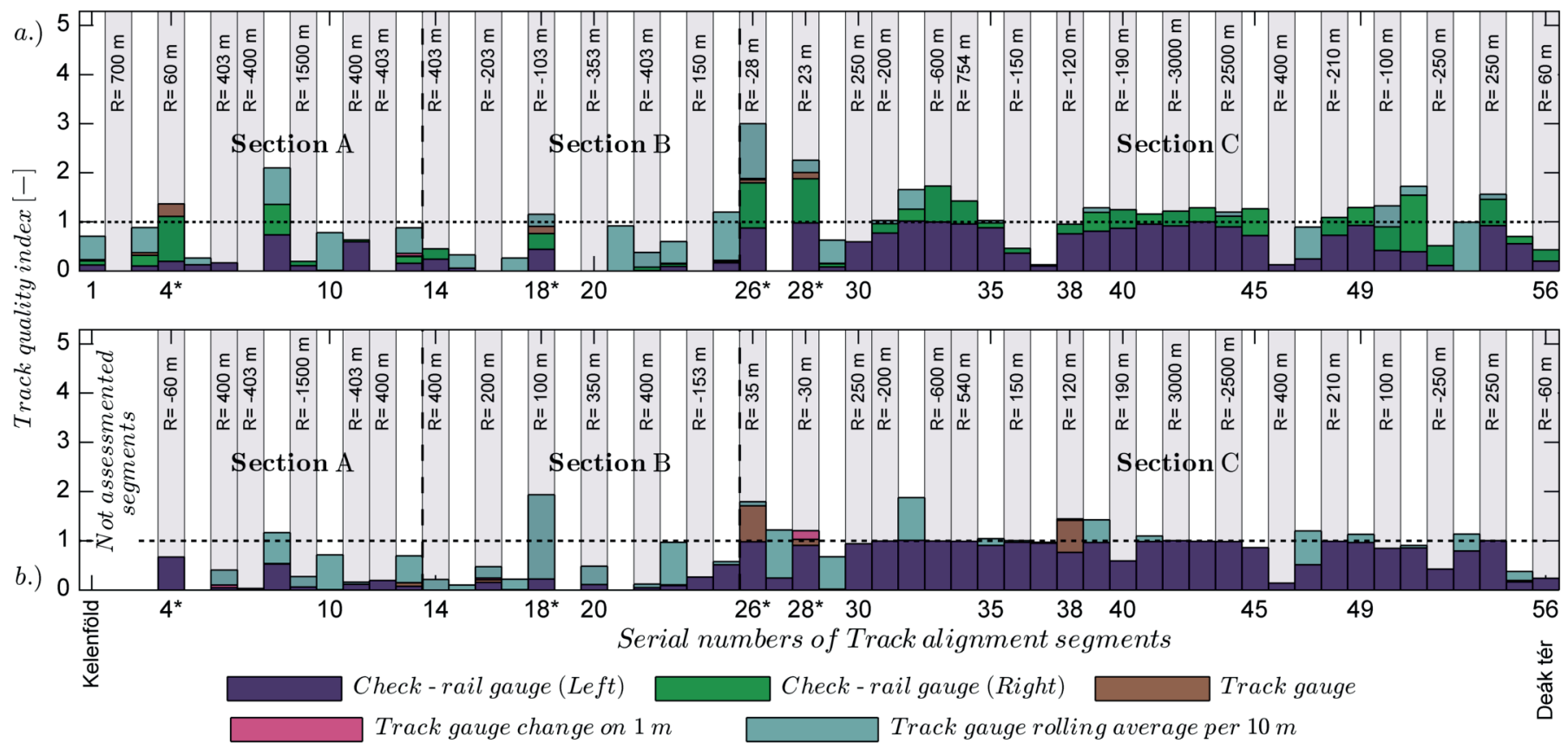

Fig. 3 Computed track quality index of alignment segments according to the results of quasi-objective condition assessment (un-loaded track geometry measurement by TrackScan [14]): a.) on right-sided track, b.) on left-sided track; * significant rail sidewear on curve

The results of left-sided track subjective condition assessment are shown in Fig. 2. At the top of diagram, the built, rebuilt years of segments are illustrated. In the diagram the homogeneous track sections are separated by vertical dash lines, as well as the curve segments of track are coloured by grey background. Every curve segment has the information about its Radius on the top part of the second trace.

Each geometrical track segment is assessed based on the developed criterion system, but only the weighted average category points is presented in Fig. 2. Minor differences are observed between the left and the right-sided track. Only those curved track segments have high score in deterioration rate, where significant rail wear is observed (See in Fig. 2: Segment 4*, 18*, 26*, 28*), or the track irregularities can also be seen in visually perceptible manner (See in Fig. 2: Segment 18*, 48). The segments indexed between 49 and 56 are renovated couple years ago, so they show homogeneous condition. (After assessments carried out, the track section between Móricz Zsigmond tér ('MZs') and Szabadság Bridge was renovated in summer 2016)

\subsection{Quasi-objective method}

TrackScan Track Geometry Meter Device with electromechanical sensors [14] is used for the Quasi-objective Track Condition Assessment. This device is suitable for measuring track geometry in unloaded state, so it is not suitable to determine the defects forming from track-vehicle dynamic interaction. Therefore, this method is called partly (quasi) objective condition assessment.

Every line segments (about 5500 track meter), which are shown in Fig. 2, are investigated by using TrackScan too. The measured data is evaluated based on the permissible geometrical deviation of the measured track parameters. It should be noted the BKV does not have exact regulation in connection with assessment of the data of track geometry measuring trolleys. An individual track parameter tolerance system is developed, which based on the measurements carried out. The investigated track parameters are the following: Track gauge; Track gauge change per $1 \mathrm{~m}$; Track gauge rolling average on $10 \mathrm{~m}$; Superelevation; Twist on $2 \mathrm{~m}$ base chord and Check gange. Some track parameters, which are measured by TrackScan, is not applicable due to the unloaded measurement condition. The track lateral and vertical irregularities cannot be determined exactly in every case due to the short chord of the device. Therefore, these parameters were not used during the assessment.

The carried admissible limits for track parameters is partly based on the regulation of Budapest Public Transport Ltd. [15]

The segment-based evaluation is applied in the case of quasiobjective assessment too. The length of local defects is specified from data of track geometry measurements. The individual defects-lengths is compared with the full length of the examined segments to compute the defect rate separately per track parameters. Track quality index of the whole line or its sub-section is computed by weighting the defect-lengths with the lengths of the segments using same weight in the case of each track parameter. The results of quasi-objective track condition assessment are shown in Fig. 3. The first diagram illustrates results carried out on the right-sided and second the left-sided track. (In the case of left-sided track the section between segment 1 and segment 3 left out from the measurements due to technical reasons.)

Among the curved track segments 4*, 18*, 26*, 28*, 38 have significant peaks in deterioration level. (Refer to section 4.1). On these segments significant rail vertical-, and side wearing, 

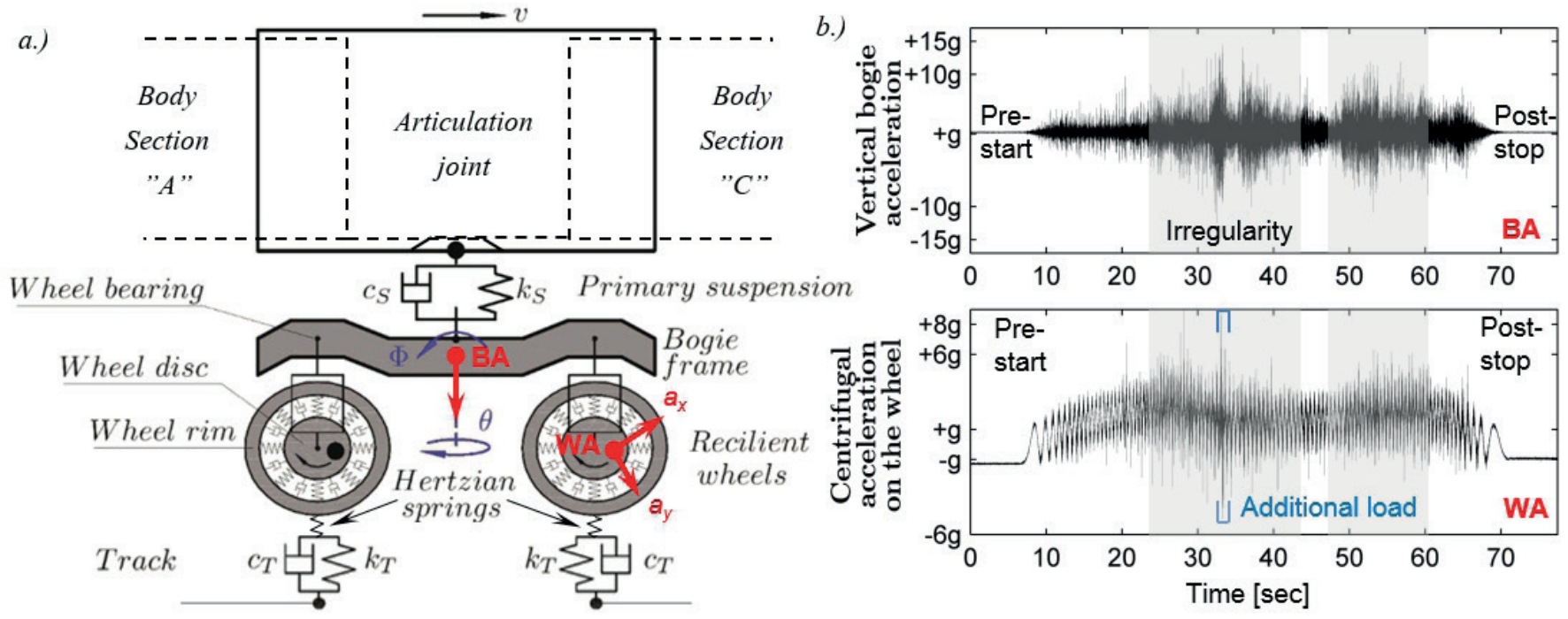

Fig. 4 Multibody dynamic model of vehicle-track interaction: a.) position and sensing direction of the sensors on the instrumented Jacobs-type bogie; b.) at the top recorded vertical acceleration signal on bogie side-frame (Sensor BA); at the bottom recorded centrifugal acceleration signal on wheel disc (Sensor WA)

as well as corrugation can be observed. It should be noted that the superstructure of the segment 26 and 28 are different from the others. On segment 4 in Section $A$ the grooved rail head is in poor condition. It is broken and its considerable lengths is missing. This is demonstrated by the high value of check-rail gauge too. On segment 18 in Section $B$ there was an accident before half year of measurements, where a tram carriage derailed. After accident this segment was renovated, but a significant alignment faults remained, which is clearly demonstrated by the high value of track gauge parameter index. The section $C$ was rebuilt the latest, whose newest part is between Segment 49 and 56.

Considerable fault cannot be found on this part of Section $C$, but the measured rail-check gauge exceeds the admissible limits in significant length (more than 90\% defects rate). The reason of this high rate is that track is built with $1 \%$ cross sectional gradient in straight section due to drainage, so significant vertical and side wear have been formed on the outer rail in each track. In segment 38 of left-sided track reduced track gauge is measured, which can be construction failure.

\section{Track condition monitoring in loaded state}

A unique vehicle dynamics measurement set-up is applied in addition to the existing condition monitoring techniques for the Objective Track Condition Assessment purposes.

Recently modern electronics and the development of robust sensors, which are compact and robust enough to be mounted underneath in-service vehicles, made the rolling-stock-based infrastructure monitoring possible. In this case, the estimation of track quality is based on the evaluation of vehicle running characteristics rolling on faulted track sections. In the case of conventional railways, the European Norms 13848 series [16] partly defines approaches for evaluation of track quality from vehicle dynamics measurement, but there are no standards available in the case of tramway operation, which significantly differs from conventional railways in both rolling stocks and infrastructure.
The axlebox [17] [18] [19] [20] [21], bogie side-frame and car body mounted inertial sensors [21] to [24] are commonly used for measuring vehicle dynamics behaviour. The irregular vehicle movement can refer to track irregularities and different exciter frequency components are registered in the recorded signal, depending on the defect types. There are numerous solutions in literature to detect different wavelengthtrack defects by using the techniques of signal processing, for instance conventional Fourier Transform [18] [25] [26] and wavelet approaches [9] [27] to [29]. Due to the fact that in tramway operation the sensors cannot be mounted on axle boxes, so a not-commonly used vehicle dynamic measurement set-up is carried out by the Authors [8] [30] to detect poor track geometry and structural problems.

\subsection{Experimental setup and data collection}

The GANZ type articulated tramcar was used for the test. It has 3 body sections, two not-driven Jacobs-type bogies and two driven bogies, one at each end of the vehicle. Three-axes accelerometers are mounted on the one hand on each wheel disc within a not-driven bogie (named WA), on the other hand, on the middle part of the bogie side-frames (named BA) under the pivot point of car body. The position and sensing directions of the sensors are given in Fig. 4a. The sensors $W A$ sense the $a_{z}$ axial acceleration pointing outward from the plane of wheel, the $a_{x}$ tangential and $a_{y}$ radial acceleration. The sensors BA on bogie-side frame measure the vertical and lateral accelerations.

The rotating wheel mounted accelerometers can work as a revolution counter, if considering the wheel diameter, both the vehicle velocity and travelled route can be computed [8]. At the first test period the instrumented vehicle works as a dedicated inspection vehicle, in order to keep the constant velocity $( \pm 5 \%)$ and help to determine the influencing factors on results. 
a)

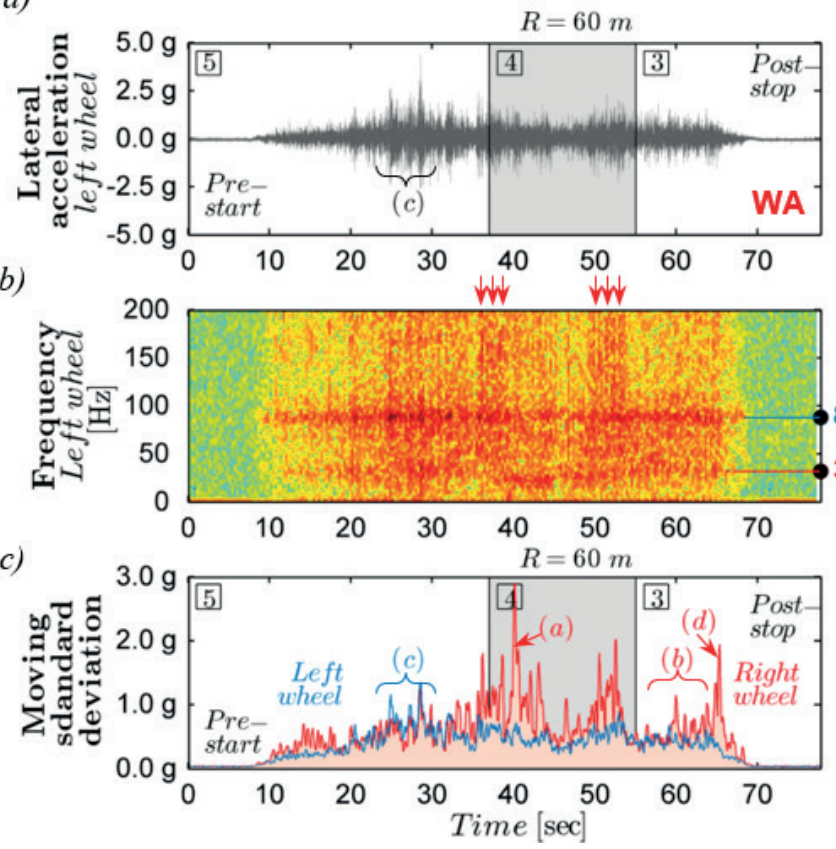

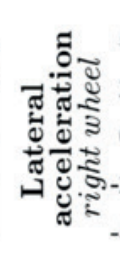

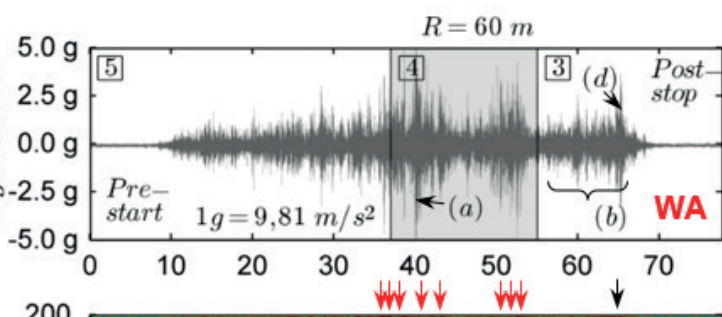

d)
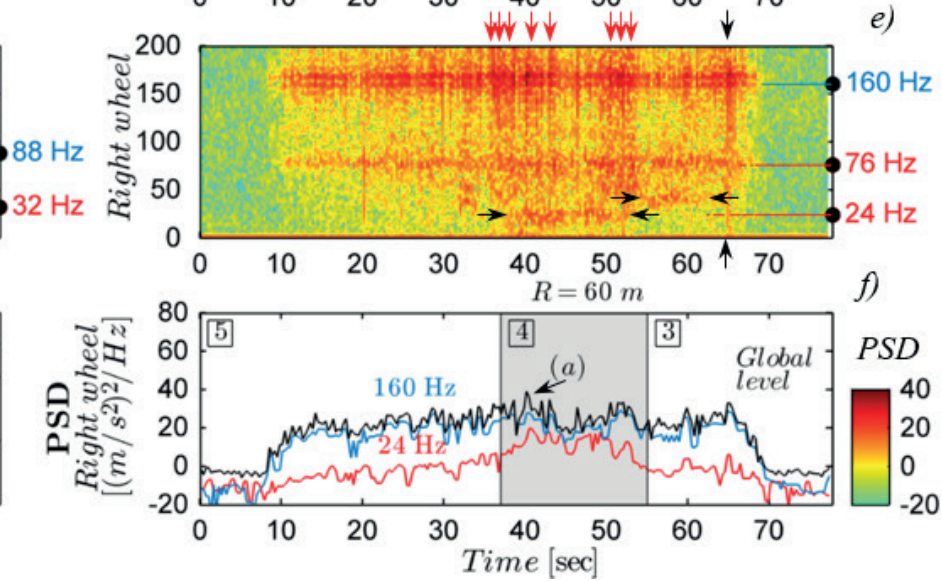

Fig. 5 Analysis of the first wheelset lateral accelerations recorded on tram line 49 from segments 5 to 3; Acceleration time histories a.) left-, d.) right-sided wheel; STFT Spectograms b.) left-, and e.) right-sided wheel; c.) Moving standard deviation of two time histories ; f.) PSD corresponding to right-sided wheel

The accelerometers are used with the maximum sampling frequency of $400 \mathrm{~Hz}$. These tools are suitable to record the impact of track irregularity with the wavelength between 0.09 and $25 \mathrm{~m}$ [31] considering Nyquist-Shannon sampling theorem and the speed range used in tramway operation. In the future, the sampling frequency is going to set to $2500 \mathrm{~Hz}$, to be suitable for measuring minor wavelength track defects too.

\subsection{Data processing}

There are two main sources of forming additional loads in vehicle-track interaction: one part comes from the running behaviour of the vehicle and the other part is generated, when the vehicle runs on faulted track section. The evaluation of recorded vibration on different parts of vehicle suspension system is based on detecting the dominant vibration frequencies and analysing amplitudes of measured signals. The different wavelength track defects excite different vibration frequencies on different parts of vehicle suspension system (See Fig. 4a). The short-wavelength track defects, including the isolated faults, cause broad band excited vibration recorded on sensors WA, while long-wavelength track defects generate low-frequency vibration, which can be detected by sensors $B A$.

The wavelength of given track defect can be computed from the actual vehicle velocity $(v[\mathrm{~m} / \mathrm{s}])$ and identified excitation frequency $f[\mathrm{~Hz}]$ :

$$
\lambda=v / f
$$

The excitation frequency is analysed by using the ShortTime Fourier Transform (STFT) [25] with the time window length of $0.3 \mathrm{~s}$.

\subsection{Observation of track defects}

Fig. 5. and Fig. 6. illustrate the results of vehicle dynamics measurements between the alignment segments no. 5 and no. 3 of right-sided track. The segments are numbered according to Fig. 2. and Fig. 3. and the curved tracks are coloured by grey background with the value of radius.

Among the sensors WA only those are analysed during the measurement, which are on both sides of the first-wheelset within the instrumented bogie in travelling direction. Both figures can be divided into two main parts: left-sided traces (except left bottom on Fig. 5.) refer to left rail, while rightsided ones refer to right rail. Three traces per side show the track quality of the rails. The first illustrates acceleration time history, the second one illustrates the STFT power spectrum (PSD) of the signal, and in the last one there are three different plots: the time evaluation of the global level of the measured quantity and the fundamental and dominant frequency components based on PSD of frequency range.

\section{A.) Analysis of acceleration time history}

The acceleration peaks identified on left and right side are analysed and compared. There is one right-sided curve (segment no. 4) within this investigated track section. The left-sided wheel corresponding to the inner rail, while the right-sided wheel to the outer rail. In this curve, the wheelset is oriented to outer rail and the wheel flange is in contact to the rail gauge side, which causes significant differences in moving standard deviations of the left-, and right-sided wheel in Fig. 5c. Furthermore, a significant outstanding value can be observed at the place of (a) on right rail at $40 \mathrm{~s}$ (See Fig. 5c. and Fig. 5d), which refers to a misalignment rail illustrated in Fig. 7. 
a)

b)
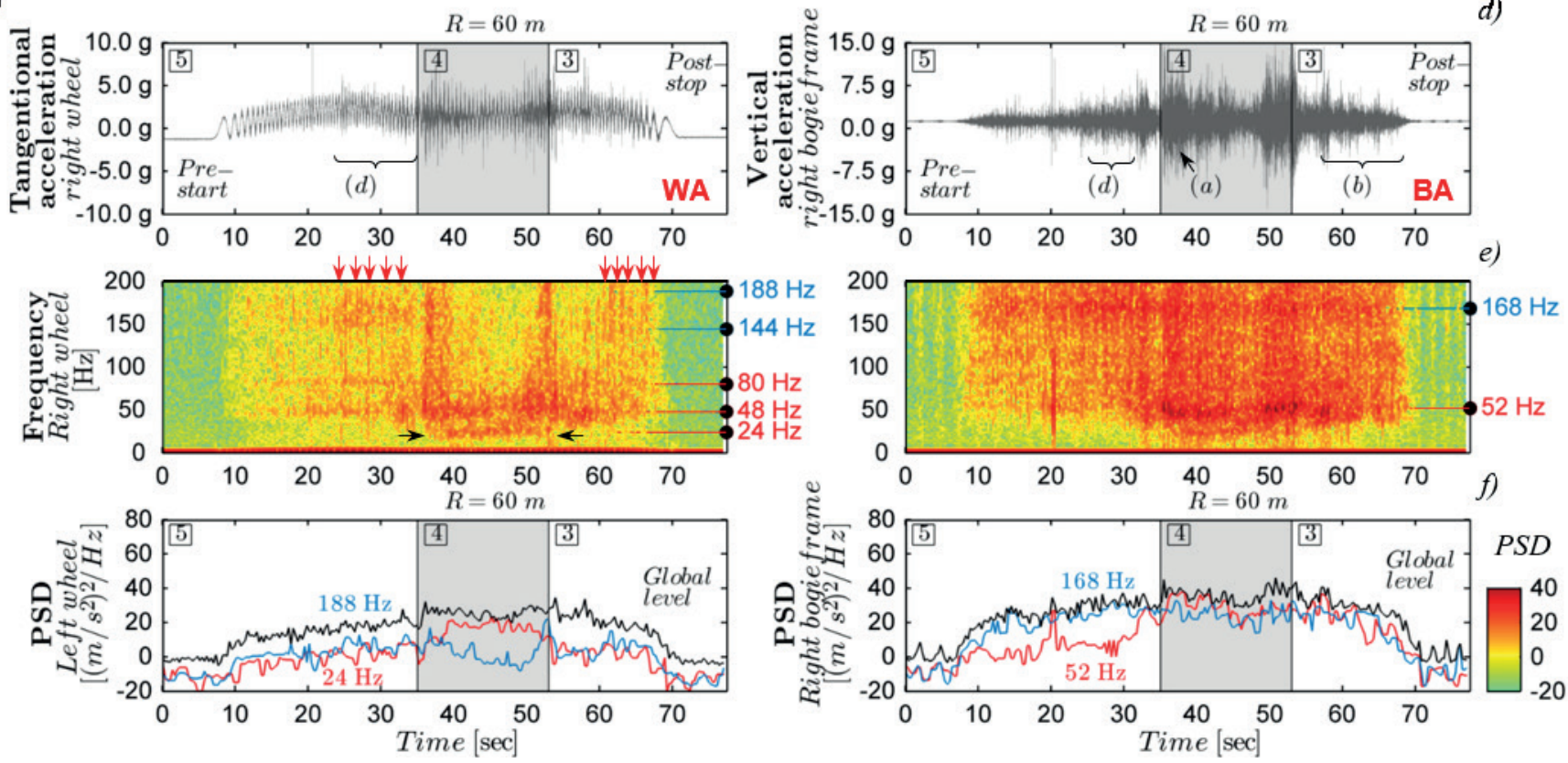

Fig. 6 Comparing the accelerations recorded on first-right wheel and same side bogie side-frame on tram line 49 from segments 5 to 3 ;

a.) wheel tangentional acceleration, d.) bogie side-frame vertical acceleration; STFT Spectograms corresponding to b.) wheel, and e.) bogie side-frame; PSD corresponding to c.) wheel, f.) bogie side-frame

In the straight section no. 3 the grooved head of right rail has significant side wear (See Fig. 8), which generate significant differences between measured lateral accelerations on both sides. (See (b) and (d) on Fig. 5c and Fig. 5d).

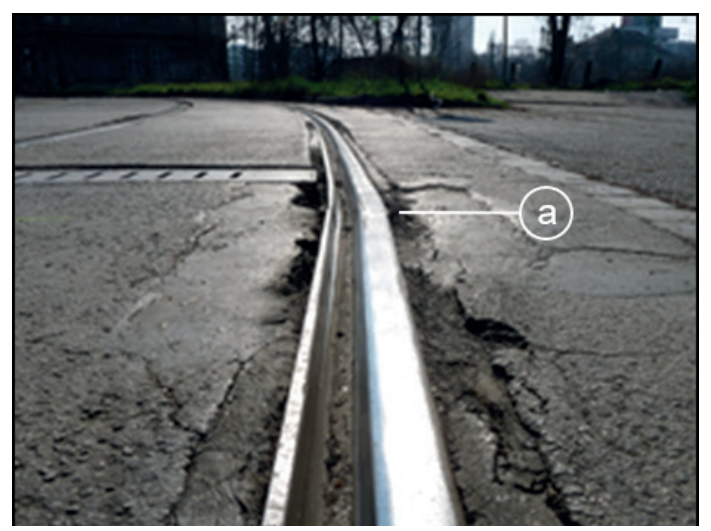

Fig. 7 Lateral misalignment on the outer rail (right side) in curved segment (See Fig. 5c. outstanding values at the place of (a) about $40 \mathrm{~s}$ )

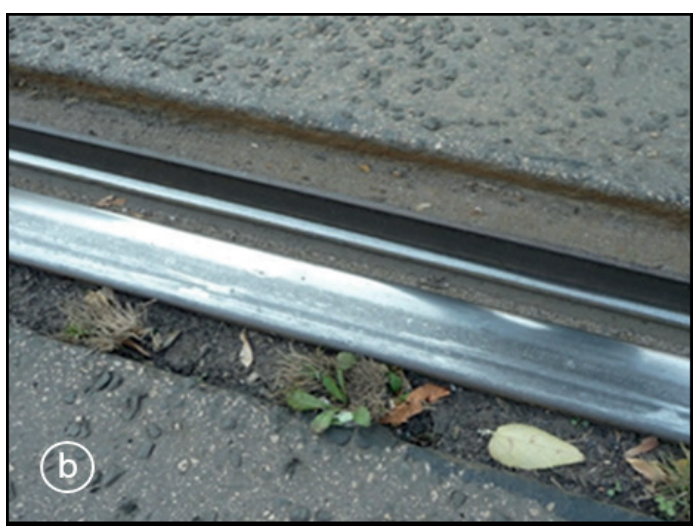

Fig. 8 Sinked rail and laterally weared rail groveed head (See Fig. 5c. outstanding values at the section of (b) between 55-63 s)

\section{B.) Analysis of spectrograms}

By observing the spectrograms in Fig. 5, two distinct groups of track defects can be easily distinguished: those which are isolated and those which appear along a certain track length. The first group may include not only rolling contact fatigues, but also track singularities such as welded joints, glued joints, turnouts or diamond crossings. Depending on the amplitude of the accelerations they cause, they may be considered as track defects too. The second group mainly includes vibration modes associated to different track configurations (e.g. ballast or slab), track vertical misalignment and rail corrugation. The first group presents a column-wise appearance in the spectrogram (see spectrogram of Fig. 5e. at $65 \mathrm{~s}$ ), since they produce a short time duration impact on the wheel, thus exciting a wide range of frequencies. On the contrary, the second group appears as a horizontal band covering specific frequency ranges (see spectrogram of Fig. 5e. between 40 and 50 s) [18].

Track defect can also result in dominant frequencies, when they carry relatively high energy peak among all frequencies found in the spectrum. In the curve section the wheelset is oriented to outer rail and the wheel flange is in contact to the rail gauge side, which causes a broad band excitation on outer rail (see red arrows on Fig. 5b and Fig. 5e). This is reflected by the spectrogram red colors in column-wise.

An approximately $40 \mathrm{~Hz}$ excitation is observed on the straight alignment segment number 3, (see Fig. 5e between 55 and $63 \mathrm{~s}$ ) which refers to the contact between the wheel flange back and a grooved rail-grooved head. This situation can be formed only on faulted track section (See Fig. 8). 
a.)
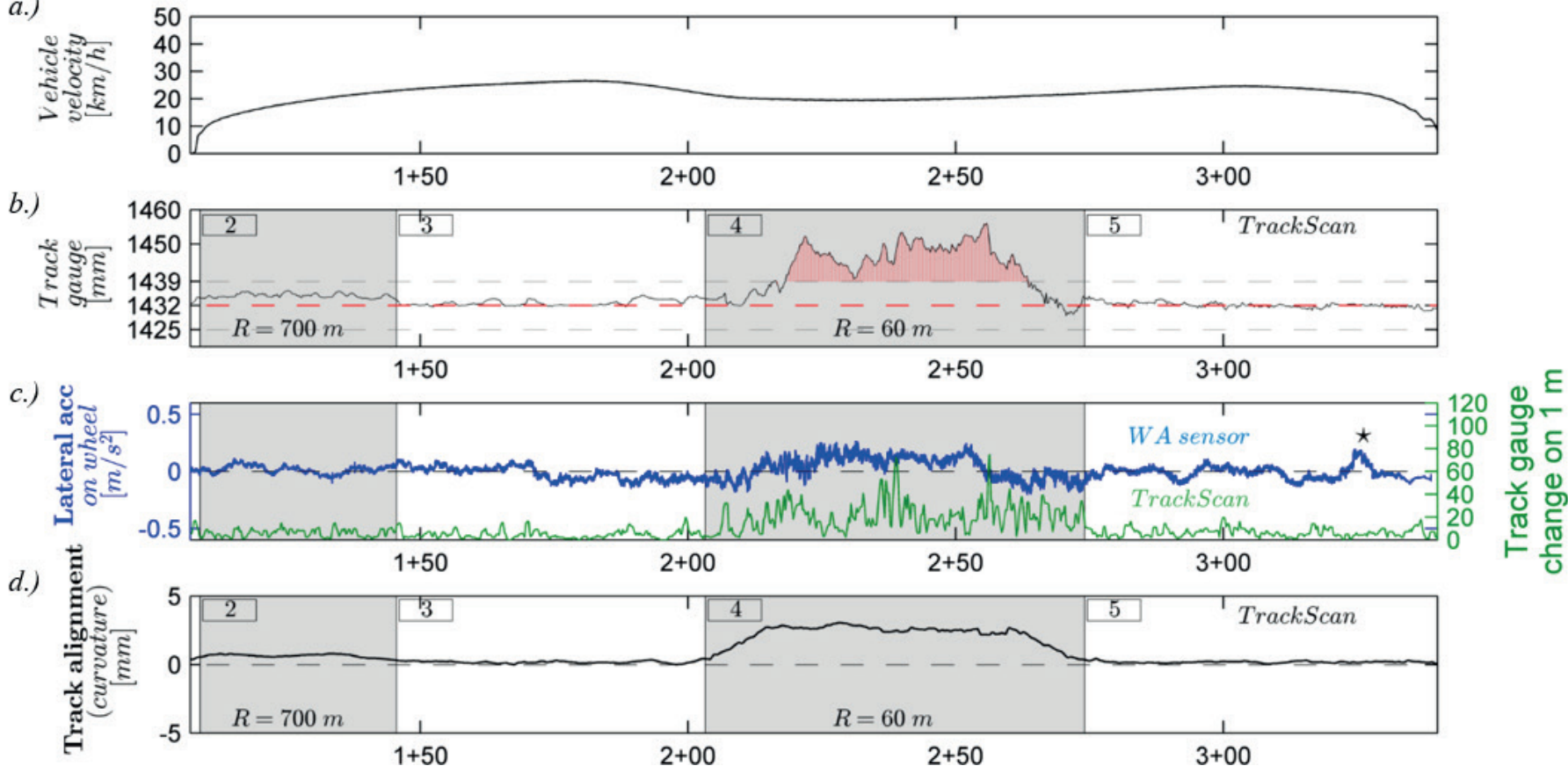

Fig. 9 Comparison of measurement results under un-loaded and loaded condition betwwen alignment segments 1 and 5 on right-sided track;

a.) vehicle velocity computed from wheel tangential $\left(a_{x}\right)$ and radial acceleration $\left(a_{y}\right)$; b.) track gauge measured by TrackScan; c.) filtered lateral acceleration recorded on first-left wheel; c.) the measured track alignment by TrackScan. (x axis of each diagram presents the track chainage in hectometre).

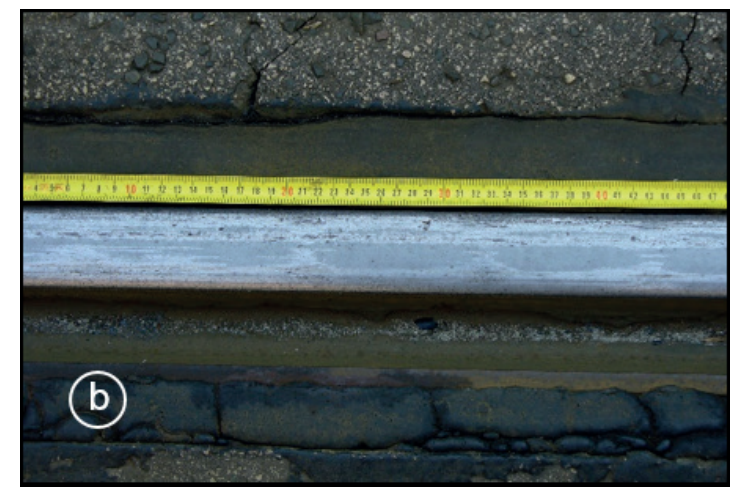

Fig. 10 Vertical wear of rail head. The wheel flange running on the bottom of groove of the grooved rail. Long-wavelength rail corrugation on rail head. (See Fig. 6d. outstanding values at the section (b))

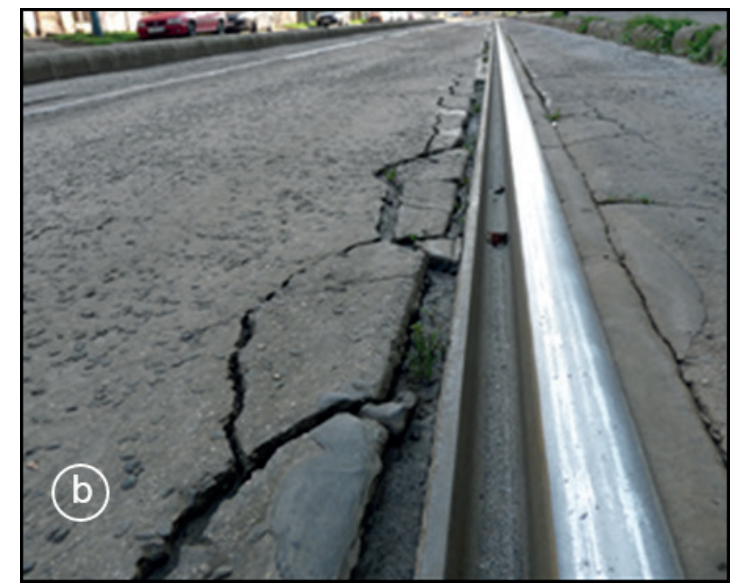

Fig. 11 On the straight segment 3, the sinked rail and fragmented pavement (See Fig. 6d. outstanding values at the section (b) between 58-68 s )
The measurement data of the sensors mounted on the same side of wheel and bogie frame are compared to each other on Fig. 6. In the case of sensor $W A$ the tangential, while in the case of sensor $B A$ the vertical accelerations are investigated.

The track defect generated vibration can be observed on both the wheel and bogie side-frame. However, the instrumented vehicle has resilient wheels, which have a special filtering aspect in vertical direction. It causes the reduction of the high frequency background noise and resulting the easier detection of track defects caused vibration. In the case of bogie side frame mounted sensors this impact is additionally excited by the second axle within the bogie. The recorded vibration on sensor $B A$ excites the whole frequency range in spectrogram, because the instrumented vehicle has poor riding behaviour (there are no significant damping elements between bogieframes and axles). Nonetheless, two frequency peaks can be observed partly at 52 and $168 \mathrm{~Hz}$. These components can be identified more clearly on sensor $W A$ than the $B A$ thanks to their higher resonance level.

The exciter wavelength can be computed from the actual vehicle velocity and the identified resonant frequencies according to equation (1). The instrumented vehicle runs at $20 \mathrm{~km} / \mathrm{h}$, the identified resonant frequency is about $50 \mathrm{~Hz}$, which means an approximately $11.1 \mathrm{~cm}$ wavelength rail corrugation (See Fig. 10).

Before and after the curved segment no. 4 a periodic excitation (red "vertical lines" in spectrogram on Fig. 6b.) can be seen between 48 and $200 \mathrm{~Hz}$, in addition to the approximately $48 \mathrm{~Hz}$ resonant frequency ("horizontal line"). The periodically repeated vertical lines in spectrogram mean hitting effect per $1-1.5$ seconds. The vehicle runs at $20 \mathrm{~km} / \mathrm{h}$, so the hitting effect 
can be identified per 4-6 meters, which is approximately equal to the distance between the fastenings of the track in straight section. Therefore, the power of these vertical lines refers to the condition of the fastenings. On the straight segment no. 3 the rail head is such intensively worn that the wheel flange runs on the bottom of the groove of grooved rail, which increases even more the above mentioned effect (see Fig. 11).

Observing spectrograms on Fig. 5 two different main frequency components are dominated in the case of both rails on the whole section: on the left side 32 and $88 \mathrm{~Hz}$, while on the right side 76 and $168 \mathrm{~Hz}$. It is the authors' opinion that this is due to the fact that there is a forming resonance between the steel plate and wheel disc. The instrumented vehicle has resilient wheels and a steel plate provides fixing accelerometers to the wheel. It has two conical structured spacers, which fit into the two bore-holes of wheel disc. Recently the steel plate is modifying to eliminate this side effect.

\section{Validating and comparison of results}

There is relation between the results of subjective and the measurement based objective type assessments (for instance: the deterioration rate of curved segments in poor condition, or the segments from 49 to 56. in good condition). Nonetheless, the subjective assessment is only suitable for identifying safety-critical defects, so it is in a restricted manner comparable to measured data based assessments.

Comparing the assessment methods, it should be noted there are differences between measured data under loaded (objective) and un-loaded state (quasi-objective). The un-loaded track geometry measurements do not contain the dynamic response of track, only provide recording static state of track. Rightsided track segments from 1 to 5 (about $250 \mathrm{~m}$ ) are illustrated in Fig. 9. with detailed data of measurements under both loaded and un-loaded states. In the case of rolling stock-based infrastructure monitoring the tramcar runs at nearly constant speed between 20 and $25 \mathrm{~km} / \mathrm{h}$ on this section apart from the acceleration and deceleration zones. Between the two types of measurements there are about 3 months.

Fig. 9. is divided into four traces. In the first one the vehicle velocity computed from the recorded tangential and radial acceleration on wheel is shown. In the second one the track gauge measured by TrackScan is represented in the function of chainage in hectometre. Furthermore, the admissible limits are also shown in this trace to detect signal parts, which exceed the limits. The third trace illustrates two plots: the low-pass filtered lateral wheelset acceleration (cut-off frequency $5 \mathrm{~Hz}$ ) and the track gauge changing per $1 \mathrm{~m}$ measured by TrackScan. The fourth one presents the track curvature measured by TrackScan. The segments are continuously numbered (according to Fig. 2. and Fig. 3.) along the investigated track section. The curved segments are coloured by grey background with the value of radius.
The track gauge signal exceeds the upper limit (1439 mm) in significant length at the place of number 4 curved segment. The acceleration signal belonging to this curved segment also consists of peak values close to the parts, where track gauge signal exceeded its limits. The peak values refer to track irregularities in lateral alignment. The signal of track gauge changing per $1 \mathrm{~m}$ has significant peak values close to outstanding values of lateral acceleration within this curved section. Based on this and the results of both Subjective, Quasi-objective methods it is pointed out that the segment number 4 is in poor condition.

The filtered lateral acceleration signal at the chainage between $3+20$ and $3+30$ has peak (*signed the place in Fig. 9c), which is caused by a sinking sewer close to track.

\section{Further issues}

This paper deserves further investigation that will focus on the following areas.

Based on the experiences of measurements the short and long-wavelength-track defects can be identified without using the techniques of signal processing, but in that cases, when multiple defect occurred on the same track section their usage is necessary. In order to separate different types of track defects formed on the same track section, on the one hand the background vibration noise should be reduced, on the other hand dynamic transfer characteristics of the vehicle-track system should be identified based on a simplified dynamic model (See Fig. 4a.). A more detailed analysis should be carried out to define, what the transfer function of the whole dynamic system (vehicle track interaction) is. Also, its subsystem should be investigated separately, when the vehicle runs on different types of track defects.

In order to determine deterioration rate of track sections from vehicle dynamic response only, reference measurements should be carried out on similar track in good condition. The differences from the reference can characterise the quality of the investigated track section. As long as there are no sufficient measurement data from vehicle dynamics measurements available, the subjective and quasi-objective methods can provide an opportunity to verify and validate the data of dynamic measurements.

The investigation of influencing factors (changing condition of vehicle, measurement speed, different track configurations) on vehicle dynamic measurements should be carried out by passing various runs passed on same track at different speeds.

\section{Conclusions}

The three methods introduced in this article can provide a certain level of service, while taking into account the given conditions. Subjective track quality scoring is only suitable for identifying safety-critical defects. Un-load track geometry measurement based assessment works well in the case of controlling newly-built track alignment, but the rolling stock 
measurements-based condition assessment is absolutely necessary for planning preventive maintenance activity. Taking the structural specification of rolling stocks operated in Hungarian tramways into account, a unique vehicle dynamics measurement setup is developed, in which accelerometers mounted on the wheel discs are also applied, in addition to conventional solutions. Although the introduced vehicle dynamics measurement system does not provide exact data of track geometry, but the high accelerations are associated with poor track geometry and structural problems (faulted welds and rail joints, foundation problems).

The instrumented vehicle mentioned above has poor riding behaviour, which means that it has high-resonance vibration during operation due to its old constructional arrangement. Although the axlebox and bogie side-frame mounted sensors are commonly used worldwide to identify track irregularities in vertical and horizontal plane, but in these experiment the wheel disc mounted sensors provide better solution for monitoring tramway track.

Regarding the identification of vertical track irregularities, it can be concluded that without using signal processing, the rotating wheel mounted accelerometers have more accurate frequency information about vehicle dynamic response on track defects, than the bogie frame mounted sensors (compare the vibration levels of wheel and bogie frame on the second traces on left and right side on Fig. 6.). It is also observed that the amplitude of the recorded signal can refer to the condition of the isolated structural elements along the track. The highest peaks of recorded signal are associated with poor condition. Fig. $6 \mathrm{a}$ consists of outstanding values before and after of curved section, which means hitting effect per about 4-6 m, which is equal to the distance between the fastenings of the track. Another important conclusion is that the recorded vibration in plane of wheel can refer to the wavelength of rail corrugation.

Regarding the identification of lateral track irregularities, it has been pointed out that the wheel mounted sensors are suitable to detect the contact between the rail and wheel flange as well as rail and wheel flange back. These contacts cause excitation in short range of frequencies and can refer to lateral track irregularity or structural problem.

This vehicle dynamic measurement system is cheap to implement and no significant modification of the vehicle is required. Therefore, in-service vehicles equipped with this system and GPS may serve a good opportunity for monitoring tramway track, while it is running. Multiple passes over same track section can contribute to establishing safe transport systems.

\section{Acknowledgement}

The Authors intend to thank the Budapest Public Transport Ltd. (BKV) and METALELEKTRO Measuring Technique Ltd. for assuring of the tramcar and the TrackScan as well as to B. Figura and V. Gáspár for assistance in the measurements.

\section{References}

[1] Roberts, C., Goodall, R. M. "Strategies and techniques for safety and performance monitor,ing on railways". In: Proceedings of the Seventh IFAC Symposium on Fault Detection, Supervision and Safety of Technical Processes, SAFEPROCESS'09, Barcelona, Spain, 30 June-3 July, 2009, pp. 746-755. 10.3182/20090630-4-ES-2003.00123

[2] Coenraad, E. "Modern railway track". (Digital Edition, version 3.1), Delft University of Technology, 2014. http://esveld.com/Merge_MRT_3.3SelectionWeb.pdf

[3] Iman, S., Alireza, A., Uday, K. "Track geometry degradation and maintenance modelling: A review". Proceedings of the Institution of Mechanical Engineers, Part F: Journal of Rail and Rapid Transit, pp. 1-30. 2016. 10.1177/0954409716657849

[4] Mundrey, J. S. "Railway Track Engineering". Chapters 13 and 17., Tata McGraw-Hill, New Delhi, India. 2010.

[5] Konstantinos T. "The Railway Track and its long-term behavior: A Handbook for a Railway Track of High Quality". from Section IV to Section VI. Springer. New York, USA. 2013.

[6] Ward, C. P., Dixon, R., Weston, P. F., Stewart, E. J. C., Charles, G., Goodall, R. M., Roberts, C., Mei, T. X., Li, H. "Condition monitoring opportunities using vehicle-based sensors". Proceedings of the Institution of Mechanical Engineers, Part F: Journal of Rail and Rapid Transit, 225(2), pp. 202-218. 2011. https://doi.org/10.1177/09544097JRRT406

[7] Foeillet, G., Coudert, F., Delcourt, V. "IRIS 320 is a global concept inspection vehicle merging engineering and $\mathrm{R} \& \mathrm{D}$ tools for infrastructure maintenance". In: Proceedings of the Eight World Congress on Railway research, Seoul, South Korea, 18-22 May 2008. http:/www.uic.org/ cdrom/2008/11_wcrr2008/pdf/I.3.1.3.1.pdf

[8] Vinkó, Á., Bocz, P. «Practical experience and in-service vehicle dynamics measurements based maintenance strategy for Tramways Infrastructure". In: International Conference on Road and Rail Infrastructure, CETRA 2016, Šibenik, Croatia, May. 23-25, 2016, pp. 335-341. https:// doi.org/10.13140/RG.2.2.29755.82729

[9] Hitoshi, T., Yasukuni, N., Akira, M., Takeshi, M., Hirotaka, M. "Condition monitoring of railway track using in-service vehicle”. In: Reliability and Safety in Railway, (Perpinya, X. (Ed.)). Chapter 12, pp. 333-356. InTech. 2012. https://doi.org/10.5772/35205

[10] Weston P., Roberts, C., Yeo, G., Stewart, E. "Perspectives on railwaytrack geometry condition monitoring from in-service railway vehicles". Vehicle System Dynamics. International Journalof Vehicle Mechanics and Mobility, 53(7), pp. 1063-1091. 2015. https://doi.org/10.1080/004231 14.2015.1034730

[11] Reng-Kui, L., Peng, X., Zhuang-Zhi, S., Ce, Z., Quan-Xin, S. “Establishment of Track Quality Index Standard Recommendations for Beijing Metro". Discrete Dynamics in Nature and Society. Article ID 473830. 2015. pp. 1-9. https://doi.org/10.1155/2015/473830

[12] Kormos, Gy., Barna, Zs., Bocz, P. “A közúti vasúti vágányok geometriai diagnosztikájának és minősítési módszerének kidolgozása”. (Development of condition monitoring and assessment models for tramway track infrastructure), Budapest University of Technology and Economics, Department of Highway and Railway Engineering, Research and Development project, 2004. (in Hungarian)

[13] Gáspár, V. "Monitoring and Condition Assessment of Tramway Tracks in the aspect of the deterioration rate". BSc thesis In Budapest University of Technology and Economics, Department of Highway and Railway Engineering. 2016. (in Hungarian).

[14] METALELEKTRO Measuring Technique Ltd. "Handbook of TrackScan Me 4.02 Track Geometry Measuring Trolly”. http://www.metalelektro. $\mathrm{hu} /$ merestechnika/?lang=eng\&menu=95\&pid=114 
[15] Budapest Public Transport Ltd. "Handbook of Tramway Track construction and Maintenance". Budapest, Hungary. 2000. (In Hungarian)

[16] European Standard EN 13848-1-6: "Railway applications - Track Track geometry quality". European Committee for Standardization (CEN). ISBN: 97-8058-069-07-30, 2008.

[17] Real, J. I., Montalbán, L., Real, T., Puig, V. "Development of a system to obtain vertical track geometry measuring axle-box accelerations from in-service trains". Journal of Vibroengineering, 14(2), pp. 813-827. 2012. http://hdl.handle.net/10251/56930

[18] Salvador, P., Naranjo, V., Insa, R., Teixeira, P. “Axlebox accelerations: Their acquisition and time-frequency characterisation for railway track monitoring purposes". Measurement, 82, pp. 301-312. 2016. https://doi. org/10.1016/j.measurement.2016.01.012

[19] Lee, J. S., Choi, S., Kim, S. S., Park, C., Kim, Y. G. “A Mixed Filtering Approach for Track Condition Monitoring Using Accelerometers on the Axle Box and Bogie". Transactions on Instrumentation and Measurement, 61(3), pp. 749-758. 2012. https://doi.org/10.1109/TIM.2011.2170377

[20] Wanming, Z., Pengfei, L., Jianhui, L., Kaiyun, W. "Experimental investigation on vibration behaviour of a CRH train at speed of $350 \mathrm{~km} / \mathrm{h}$ ". International Journal of Rail Transportation, 3(1), pp. 1-16. 2015. https:// doi.org/10.1080/23248378.2014.992819.

[21] Bocciolone, M., Caprioli, A., Cigada, A., Collin, A. "A measurement system for quick rail inspection and effective track maintenance strategy". Mechanical Systems and Signal Processing, 21(3), pp. 1242-1254. 2007. https://doi.org/10.1016/j.ymssp.2006.02.007

[22] Xiukun, W., Feng, L., Limin, J. "Urban rail track condition monitoring based on in-service vehicle acceleration measurements". Measurement, 80, (2016), pp. 217-228. 2016. http://dx.doi.org/10.1016/j.measurement.2015.11.033.

[23] Shafiullah, G. M., Ali, A. B. M. S., Thompson, A., Wolfs, P. J. "Predicting Vertical Acceleration of Railway Wagons Using Regression Algorithms". IEEE Transactions on Intelligent Transportation Systems, 11(2),pp. 290-299.2010.https://doi.org/10.1109/TITS.2010.2041057
[24] Weston, P. F., Ling, C. S., Goodman, C. J., Roberts, C., Li, P., Goodall, R. M. "Monitoring lateral track irregularity from in-service railway vehicles". Proceedings of the Institution of Mechanical Engineers, Part F: Journal of Rail and Rapid Transit, 221(1), pp. 89-100. 2016. https://doi. org/10.1243/0954409JRRT64

[25] Boashash, B. "Time-frequency signal analysis: methods and applications", Longman Cheshire, Melbourne, 1992.

[26] Domingo, L. M., Giner, B. B., Martin, C. Z., Herraiz, J. I. R. "Experimental modal analysis of transverse-cracked rails-influence of the cracks on the real track behavior". Structural Engineering and Mechanics. 52 (5), pp.1019-1032. 2014. https://doi.org/10.12989/sem.2014.52.5.1019

[27] Heirich, O., Lehner, A., Robertson, P., Strang, T. "Measurement and analysis of train motion and railway track characteristics with inertial sensors," In: 14th International IEEE Conference on Intelligent Transportation Systems (ITSC), Washington, DC, 2011. pp. 1995-2000. https://doi.org/10.1109/ITSC.2011.6082908

[28] Li, Z., Molodova, M., Núñez, A., Dollevoet, R., "Improvements in Axle Box Acceleration Measurements for the Detection of Light Squats in Railway Infrastructure". IEEE Transactions on Industrial Electronics, 62(7), pp. 4385-4397. 2015. https://doi.org/10.1109/TIE.2015.2389761

[29] Caprioli, A., Cigada, A., Raveglia, D. "Rail inspection in track maintenance: A benchmark between the wavelet approach and the more conventional Fourier analysis". Mechanical Systems and Signal Processing, 21(2), pp. 631-652. 2007. https://doi.org/10.1016/j.ymssp.2005.12.001

[30] Vinkó, Á. "Monitoring and condition assessment of tramway track using in-service vehicle". Pollack Periodica, 11(3), pp. 73-82. 2016. https://doi. org/10.1556/606.2016.11.3.7.

[31] International Union of Railway. "Overview of Methods for Measurement of Track Irregularities Important for Ground-Borne Vibration". RIVAS (Railway Induced Vibration Abatement Solutions Collaborative project). 2013. http://www.rivas-project.eu/fileadmin/documents/RIVAS CHALMERS_WP2_D2_5_FINAL.pdf 